0

GeOrge FoX

UNIVERSITY
Digital Commons @ George Fox University

2014

Preparing Teacher Candidates to Serve Students From Diverse Backgrounds: Triggering Transformative Learning Through ShortTerm Cultural Immersion

Rebecca A. Addleman

Robert Ch. Nava

Tatiana Cevallos

Carol J. Brazo

Kriston Dixon

Follow this and additional works at: https://digitalcommons.georgefox.edu/soe_faculty

Part of the Education Commons 


\title{
Preparing teacher candidates to serve students from diverse backgrounds: Triggering transformative learning through short-term cultural immersion
}

\author{
Rebecca A. Addleman ${ }^{\mathrm{a}, *}$, Robert Ch. Nava ${ }^{\mathrm{b}}$, Tatiana Cevallos ${ }^{\mathrm{a}}$, Carol J. Brazo ${ }^{\mathrm{a}}$, \\ Kristin Dixon ${ }^{\mathrm{b}}$ \\ a George Fox University Portland Center, 12753 SW 68th Ave, Portland, OR 97223, United States \\ ${ }^{\mathrm{b}}$ George Fox University Salem Center, 4600 25th Ave NE, Ste 150, Salem, OR 97301, United States
}

\begin{abstract}
A B S T R A C T
This study followed 24 teacher candidates in a short-term cultural immersion field experience designed to help them reflect on their assumptions and perspectives in order to better understand the culturally, ethnically, and linguistically diverse students they will teach. Qualitative methods were informed by a phenomenological research approach to examine candidates' transformative learning experiences in a cultural immersion context. The findings are discussed within a three-stage framework of transformative learning: triggering experiences, frame of reference examination, and transformative change.
\end{abstract}

\section{Introduction}

Global educators are preparing candidates who will teach a broad spectrum of racially, religiously, culturally, socioeconomically, and linguistically diverse students. These trends raise many questions for teacher educators. How can we best prepare teachers to meet the learning needs of every student? What are the learning needs of every student-as community, nation-state, and global citizens? How can we help future teachers acknowledge and value students' funds of knowledge as a foundation for curriculum and instruction? How can we facilitate awareness and examination of teachers' own identities, assumptions, and perspectives in this pursuit?

Shaklee and Baily (2012) suggest that the final question provides a starting point for developing global educators, "we first need to uncover preexisting beliefs and experiences... helping teacher candidates 'clear the lens,' as part of teacher education preparation, is crucial to the acceptance and development of new perspectives" ("Developing," para. 2). Although it is impossible to truly "clear the lens," we must acknowledge and question these frames of reference through which we make meaning of the experiences and people around us. Facilitating this process is a crucial component of teacher education if we are to prepare candidates to meet the educational needs of diverse students. With this goal in mind, we investigated 24 preservice teachers' cultural immersion experiences to explore elements of transformative learning, including frame of reference awareness, triggered during a structured short-term practicum experience.

\footnotetext{
* Corresponding author. Tel.: +1 5035546041.

E-mail addresses: raddleman@georgefox.edu (R.A. Addleman), rnava@warnerpacific.edu (R.Ch. Nava), tcevallos@georgefox.edu (T. Cevallos), cbrazo@georgefox.edu (C.J. Brazo), kdixon@corban.edu (K. Dixon).
} 
Mezirow (2012) describes frame of reference as "the structure of assumptions and expectations through which we filter sense impressions" (pp. 81-82). In frame of reference construction, each interaction and experience adds, adjusts, or transforms a building block that reinforces the assumptions and expectations that will guide interpretations of future events. Many of the factors that collectively form our frame of reference filters are adopted without critical reflection-defined as "challenging the validity of presuppositions in prior learning" (Mezirow, 1990, p. 207). Gradually, we examine and replace childhood building blocks that are noticeably inaccurate, moving toward a more "dependable" frame of reference, which Mezirow defines as "more inclusive, differentiating, permeable (open to other viewpoints), critically reflective of assumptions, emotionally capable of change, and integrative of experience" (p. 84). However, the less visible blocks remain outside our awareness and continue to influence our expectations and reactions.

Uncovering these preexisting perspectives is essential to training educators and particularly important in settings where there are distinct differences between the formative experiences of a largely homogenous teaching force and an increasingly diverse student population. The diverse funds of knowledge that students bring to the classroom need to be utilized and expanded as foundational to the pedagogical framework rather than seen as a deficit or a temporary scaffold to teach the majority culture's funds of knowledge (Moll, Amanti, Neff, \& Gonzalz, 1992). If teachers view diverse student groups, curriculum, and instruction through a majority-culture lens, to what extent can they understand their students' frames of reference in order to effectively meet their learning needs? Without awareness and examination of this lens, teachers may minimize students' funds of knowledge and frames of reference rather than seeking to equally enrich their ethnic, national, and global identities (Banks, 2004; Villegas \& Lucas, 2002). Increasing cultural awareness and making assumptions about diversity visible provide necessary scaffolding for preservice teachers as they learn to meet the needs of all students. This study examines the transformative elements that a cultural immersion field experience can trigger in order to better prepare interculturally competent teachers.

\section{Theoretical background}

\subsection{Transformative learning}

In 1991, Mezirow introduced the "first comprehensive presentation of transformation theory" (Cranton \& Taylor, 2012, p. 5) based on his 1978 grounded theory findings on perspective transformation. Building on the work of Habermas (1971), who delineated learning into three domains: technical, practical and emancipatory, Mezirow also used Freire's (1970) concept of conscientization to inform his theory. It is Freire's highest stage of critical transivity-demonstrated by individuals who are able to think globally, critically assess perceived contradictions, and engage as agents of change-which most influenced Mezirow's transformative elements of disorienting dilemma and critical reflection (Kitchenham, 2008).

Built on the foundational concepts of constructivist assumptions, humanism, and critical social theory, Mezirow (2012) defined transformative learning as the process "by which we transform our taken-for-granted frames of reference... to make them more inclusive, discriminating, open, emotionally capable of change, and reflective so that they may generate beliefs and opinions that will prove more true or justified to guide action" (p. 75). Based on his theory, the elements of critical reflection and dialog lead to a transformed frame of reference, resulting in individual and social change. The transformative learning process is triggered by experiential data that do not align with one's current frame of reference. Instead of unconsciously filtering the data, these triggering events can prompt learners to critically reflect and discuss as they examine frames of reference.

Due to the cyclical nature of the transformative process, there is little agreement about the order of the phases (MacKeracher, 2012). From a cultural-spiritual perspective, Charaniya (2012) describes it as "a spiraling, creative, collaborative, and intertwining journey of discovery" (p. 235). Critique and debate have focused on tensions between seemingly dichotomous aspects of transformative learning theory such as cognitive vs affective, individual vs cultural, and personal change vs emancipatory (Boyd \& Myers, 1988; Dirkx, 2006; Johnson-Bailey, 2012; Kucukaydin \& Cranton, 2012; Merriam \& Kim, 2012). Cranton and Taylor suggest that these multiple perspectives need not be labeled as antithetical but can coexist in a holistic theory-experienced differently based on the individual and context, "these perspectives may simply be the result of scholars examining different facets of. .. the whole elephant" (p. 9). Mezirow's original theory has expanded as a result of the shaping influence of multiple perspectives and voices (Baumgartner, 2012).

Based on Mezirow's cognitive approach to the individual transformative process (Baumgartner, 2001; Kitchenham, 2008; Mezirow, 1990, 2000, 2012) and a comparison of his ten-phase model to Cranton's (2002) seven-phase model, we discuss the major elements of the transformative process in three stages that represent a fluid and recursive process rather than concretely defined boundaries: (a) experiences that trigger disequilibrium, (b) frame of reference examination through critical reflection and dialog, and (c) potential transformative change, plans, and actions.

\subsubsection{Stage one: Triggering experiences}

Cranton (2002) and Mezirow (2012) agree that a disorienting experience provides a trigger for transformative learning. Cranton describes it as "an activating event that typically exposes a discrepancy between what a person has always assumed to be true and what has just been experienced, heard, or read" (p. 66). While many methodologies are possible conduits of 
disequilibrium, one statement, event, or impression will not move all learners into a state of disorientation with their own value systems.

\subsubsection{Stage two: Frame of reference examination}

Mezirow characterized this stage by an awareness and assessment of frames of reference through critical reflection and dialog. According to Mezirow (2012), a frame of reference is a structure of expectations and assumptions that "selectively shapes and delimits perception, cognition, feelings, and disposition by predisposing our intentions, expectations, and purposes" (p. 82). Three of his ten phases provide a foundation for Stage two: (a) "self-examination with feelings of fear, anger, guilt, or shame," (b) "a critical assessment of assumptions," and (c) "recognition that one's discontent and the process of transformation are shared" (p. 86). Cranton's (2002) work expands frame of reference examination by including a preliminary phase of recognizing and articulating unconscious assumptions before moving to questioning and analyzing assumptions. She further scaffolds the examination process by identifying a willingness to consider different perspectives and explicitly includes dialog in the learning process: "evidence is weighed, arguments assessed, alternative perspectives explored, and knowledge constructed by consensus" (Cranton, p. 66).

\subsubsection{Stage three: Transformative change}

Cranton's (2002) delineation of transformative learning differs most noticeably from Mezirow's in the third stage. Cranton first includes a phase that bridges stages two and three: revising assumptions and perspectives. She then synthesizes Mezirow's (2012) final six phases (exploring new roles, relationships, and actions; planning action; acquiring the necessary knowledge and skills; trying new roles; building competence and confidence; and reintegrating based on the conditions established through new perspectives) into a single phase: "acting on revisions, behaving, talking, and thinking in a way that is congruent with transformed assumptions or perspectives" (p. 66).

\subsection{Cultural immersion}

Experience, local and global, is an essential component of preparing interculturally competent teachers to meet the needs of diverse students (Banks et al., 2005; Dantas, 2007; Malewski, Sharma, \& Phillion, 2012; Marx \& Moss, 2011; Quezada, 2004; Stachowski \& Brantmeier, 2002; Trilokekar \& Kukar, 2011). In a summary of the literature on community-based cross-cultural immersion experiences, Sleeter (2001) reported that White educators describe these experiences as "extremely important and in some cases much more important than their formal teacher education programs" (p. 97). However, Sleeter emphasized the insufficient body of research and unanswered questions regarding the ideal practicum length, setting, and impact on classroom practice. There remains a need for research in many areas of internationalizing teacher education including the connection between intercultural competence and cultural immersion field experiences for preservice teachers (Cordeiro, 2007; Malewski et al., 2012).

Cushner (2011) named intercultural competence "the ultimate goal for educators at all levels" (p. 606). Many educational institutions include common characteristics in their definitions of intercultural competence, such as "awareness, valuing, and understanding of cultural differences; experiencing other cultures; and self-awareness of one's own culture" (Deardorff, 2006, p. 247); however, there is not a single agreed upon definition or model in the literature (Deardorff, 2006; Spitzberg \& Changnon, 2009). In broad terms Spitzberg and Changnon define it as the "appropriate and effective management of interaction between people who, to some degree or another, represent different or divergent affective, cognitive, and behavioral orientations to the world" (p. 7). One of the goals of international cultural immersion is to promote intercultural awareness and competence by removing teacher candidates from certain home-culture norms and helping to make their assumptions about culture visible (Cushner, 2011; Dantas, 2007; Mahon \& Cushner, 2007; Marx \& Moss, 2011; Phillion, Malewski, Sharma, \& Wang, 2009), but as Bennett (2012) has often said, “Intercultural learning does not happen automatically during study abroad" (p. 90).

In preparation for this study, we explored the current literature to identify the dangers and benefits of short-term cultural immersion as well as programmatic factors that could address Merryfield's (2000) caution that "experiences alone do not make a person a multicultural or global educator" (p. 440). Experiences alone run the risk of reinforcing (a) emphasis on the visible and surface components of culture-food, fashion, and folklore approach to diversity (Banks \& Banks, 2010; Rios, Montecinos, \& Olphen, 2007); (b) cultural stereotypes and diversity as a deficit perspective (Bishop, 2005; Moll et al., 1992); and (c) patterns of white majority privilege and ethnic minority marginalization (Banks, 2006; McLaren \& Farahmandpur, 2001). Instead, we sought to minimize these outcomes through a focus on cultural engagement rather than cultural tourism, maximizing learning that values funds of knowledge and transformative citizenship-to diminish the practice of ignoring or devaluing traditionally marginalized students' culture in favor of the mainstream culture (Bruner, 1996; McIntyre, Rosebery, \& González, 2001), and instead, provide teachers with the tools to reframe their deficit views of linguistic and cultural minority students-incorporating student culture in the classroom (Bishop, 2005).

To promote cultural engagement rather than cultural tourism, immersion experiences need to incorporate practices such as preparation courses, reflective journals, and debriefing sessions that help students assess their own culture, possible difficulties that they will encounter upon entering another culture, and learning to see culture as "an answer and not a label" (Dantas, 2007; Mahon \& Espinetti, 2007; Stachowski, 2007). Planned time for guided reflection, introspection, and questioning of assumptions and beliefs is essential (Cushner, 2012; Dantas, 2007). The reported benefits of short-term 
practicum experiences, based on an emerging body of qualitative studies, included (a) increased cross-cultural awareness and questioning of personal assumptions about cultural diversity, (b) heightened empathy and improved professional knowledge about teaching diverse students resulting in a willingness to differentiate curriculum and instruction, and (c) greater appreciation and respect for differences and other cultures (Cruickshank \& Westbrook, 2013; Malewski \& Phillion, 2009; Malewski et al., 2012; Pence \& Macgillivray, 2008; Zhao, Meyers, \& Meyers, 2009). In the current study we implemented two preparation workshops, guided reflections, and peer-led debriefing sessions as we focused on evaluating the strengths and weaknesses of short-term cultural immersion as one piece of programmatic scaffolding for facilitating intercultural competence. We explored the question, "What elements of transformative learning are evident during a structured short-term cultural immersion experience?"

\section{Methods}

\subsection{Participants}

The study followed 17 female and 7 male graduate teacher candidates (23 Caucasian/1 Chinese) through a three-week practicum in Vienna, Austria or Quito, Ecuador. Ten candidates traveled to Vienna, and fourteen candidates traveled to Quito. Participants ranged in age from their early twenties to early forties and represented multiple campuses and formats (11-, 16-, and 20-month) in a Master of Arts in Teaching program at a private university in the Pacific Northwest, United States. Students had either just graduated or were in their second semester of a 16-month program. Two professors led the Ecuador team, and two professors led the Austrian team.

\subsection{Context}

The sites were selected to complement faculty expertise. Ecuador is the home of one professor while Vienna was the site of another faculty member's first international teaching experience. Faculty members accompanied each group for the entire duration of the trip and used informal and formal opportunities to act as cultural mentors (Berg, Connor-Linton, \& Paige, 2009) helping students to reflect on their learning.

\subsubsection{MAT program}

This practicum experience was the first of three clinical practice placements in the teacher education program, and was specifically designed for students to work in a setting where they were not members of the "majority culture." One of the goals of the program was for each participant to experience some of the disequilibrium that accompanies language learners in classrooms across the United States in order to help candidates better understand the culturally, ethnically, and linguistically diverse students they would teach.

\subsubsection{Pre-departure workshops}

Prior to travel, candidates participated in two half-day workshops to meet each other and focus on the differences between cultural tourism and cultural engagement, cultural norm continua (Storti, 1999), group dynamics (Felps, Mitchell, \& Byington, 2006), conflict resolution, and logistics of travel (Steves, 2009). In addition to itinerary and travel logistics, faculty provided (a) instruction and modeling on Guided Language Acquisition Design (GLAD) strategies to support English Language Learners, and (b) debriefing circles, a dialog structure adapted from Parker Palmer's (2004) clearness committees, aimed to create a space for students to process their disequilibrium without judgment or other common conversation elements that discourage critical reflection. During these "debriefing circles" of four to five members, students were instructed to listen to the focus person and ask open and honest questions, without giving advice or sharing connections to their own life experience. The teacher candidates were introduced to the debriefing circle process, participated in a shortened debriefing circle, and received written instructions to use overseas.

\subsubsection{Programmatic accommodations to promote this cross-cultural experience}

Providing candidates with the opportunity to travel and teach in cross-cultural settings necessitated programmatic adjustments. Depending on their place in the MAT course sequence, several students participated in the course Teaching Diverse and Special Populations, which the rest completed in the U.S. Several of the readings and course experiences focused on the importance of understanding marginalized populations and inclusion (Adachie, 2009; Freire, 1970; Jensen, 2009; McIntosh, 1989; Palmer, 2004; Staples, 2005).

\subsubsection{On-site experience}

In the cultural immersion strand of this MAT practicum requirement, teacher candidates spent three weeks working with school-age children in Quito or Vienna. One of our goals was to maximize candidates' engagement with members of the host culture. To that end, we placed them in home stays instead of community student housing. They shared meals with their host families; joined them for social events such as church, family celebrations, eating out at restaurants, and exploring city sights; and learned to use the public transportation system to travel between practicum experiences and host homes. Both 
groups had opportunities to sightsee on weekends. Opportunities for this were highly variable, based on country and host family.

Vienna. When the candidates first arrived in Vienna, they met their host families, began learning about public transportation and grocery shopping, and took an introductory city tour. After a few days in country, they met the teachers with whom they would volunteer and toured their assigned schools. In the university coursework sequence this practicum is the first of three, focused on 30 hours of community-based experiences with diverse populations. The second and third practicum experiences consist of student teaching placements. Because the cultural immersion experience as a whole met the course requirements, candidates were not always assigned to classrooms that represented their major area of study. In one of the four partnering schools (two international and two Austrian bilingual), the teacher candidates interacted with staff, observed classrooms, and worked with students one-on-one, in small groups, and whole-class instruction depending on their cooperating teachers' preferences.

After spending mornings in schools, candidates would meet once a week for professor-facilitated coursework and reflection in the form of debriefing circles, and three afternoons a week at an after-school student center with refugee and homeless children and adolescents, ages 4-21. They planned and participated in activities such as language tutoring, art, shopping and meal preparation, and facilitating group games.

Quito. In Quito, teacher candidates were placed with middle-class families and visited public and private schools serving lower, middle and upper-socio economic class students. Candidates spent mornings observing and assisting classroom teachers in bilingual Ecuadorian schools-both public and private. English was the major language of instruction. Teacher candidates' responsibilities included observation, one-on-one tutoring, small group instruction, discussion facilitation, lesson planning, and whole-class instruction. Then, they would return home to their host families for the noon meal before attending Spanish language classes in the afternoons.

In addition to their assigned school placements, candidates had the opportunity to visit a high-poverty community school in south Quito where they interacted with dedicated young students who had access to very little. The teacher candidates were troubled and inspired by their observations of children learning with worksheets and drill exercises who were excited about their "new" computer lab that had wires overhead, hung through windows and over a dirt road to connect to the electrical pole. This school was not indicative of the private schools and middle class public schools where they spent their mornings.

\subsection{Data collection and interpretation}

This qualitative study was informed by a phenomenological research approach (Rossman \& Rallis, 2003) and designed to investigate preservice teachers' cultural immersion experiences through the lens of transformative learning theory in order to enhance intercultural learning in future field experiences. The data for this study were collected during the second year of the university's cultural immersion program, building on initial research in year one (Addleman, Brazo, \& Cevallos, 2011). Faculty organized preparation workshops, on-site reflections, discussions, and debriefing circles to explore the emerging themes. The data that were collected, coded, and qualitatively analyzed in this study included weekly written student reflections in-country, and two transcribed focus group discussions once they returned home. The written prompts, adapted from Indiana University's Cultural Immersion Projects (L. Stachowski, personal communication, November 6, 2008), were designed to elicit candidates' stories and descriptions of their experiences, concerns, and insights. For example: Describe a critical incident that you have experienced in the past week. (Critical Incident: not necessarily a crisis; an incident that has stayed in your mind that you have been reflecting on or "mulling over" for hours or days). Other prompts dealt with similarities and differences between candidates' host and home cultures, expected and unexpected adaptations to the host culture, feelings of acceptance and awkwardness in social interactions, and connections to MAT course readings.

We compiled candidates' reflections and analyzed them for significant themes related to their cultural immersion experiences; then we analyzed these patterns in relation to the phases of Mezirow's transformative learning theory and described the ways in which participants' practicum experiences provoked disequilibrium, reflection, and transformative learning. In the coding and analysis process, we followed Creswell's (2007) definition for identifying significant statements and Van Manen's (1990) selective or highlighting approach to isolate thematic aspects of the phenomenon. To increase trustworthiness, we coded the data individually, compared our coding as a group, discussed any differences, and reached consensus on all assigned themes and significant statements.

\section{Results and discussion}

We integrated our findings within our theoretical framework and the literature in order to answer the question: What elements of transformative learning are triggered during a structured short-term cultural immersion experience? The major themes we identified in the data were (a) critical incidents as triggering events, (b) building schema through connections to theory and university coursework, (c) comparing differences-resulting in judgment, questions, and new perspectives, (d) peer processing of disequilibrium, and (e) self-discovery with a resolve to reorient. In this section, we discuss our findings through three synthesized stages of transformative learning in Fig. 1: triggering experiences, frame of reference examination, and potential transformative change. We end this section with limits to this study and possible future directions. 


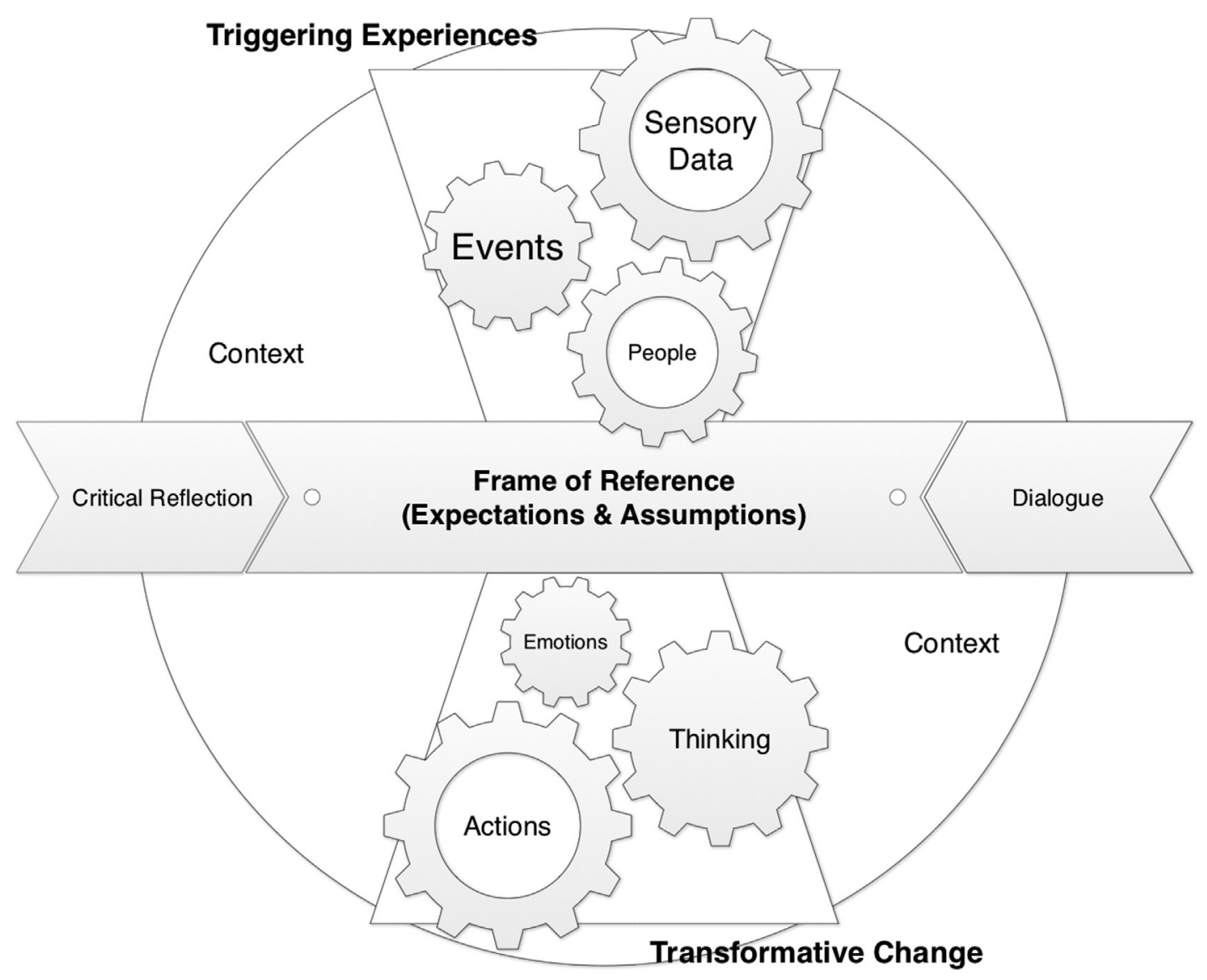

Fig. 1. Transformative learning: A meaning-making process. This figure represents the facets of transformative learning in three stages: data from triggering experiences (top), frame of reference examination through reflection and dialog (middle), potential changes, plans, and actions (bottom).

\subsection{Stage one: Triggering experiences}

In an immersion experience, disorienting events occur frequently as a result of navigating settings where the expected norm is not the reality. Candidates experienced multiple events during their cultural immersion practicum that did not "fit comfortably into [their] existing frames of reference" (Mezirow, 1997, p. 7). They experienced disequilibrium triggered by social interaction and decision-making outside the norms of their home culture-without familiar support systems and routines. While overseas practicums inherently present both challenges (e.g. privilege) and benefits (e.g. empathy), numerous triggering experiences are one of the most obvious strengths.

Taylor (1994) states that transformation "occurs out of a necessity for survival, out of a need to relieve stress and anxiety often experienced as the stranger struggles to meet basic needs" (p. 155). Although the candidates did not struggle to meet basic needs, they did experience stress and anxiety surrounding the complexity of simple tasks that would otherwise require little time or attention: the challenge of finding and purchasing food or clothing, the struggle to communicate effectively across language and cultural barriers, numerous bewildering moments on public transportation, faux pas due to unexpected cultural norms, and the frustration of unmet expectations.

Strong emotions characterized the disorienting event reflections, triggered by language challenges, cultural differences, and unmet expectations. Candidates experienced empathy as the central positive emotion and a long list of negative emotions, including feelings of being overwhelmed, embarrassed, frustrated, fearful, withdrawn, isolated, stupid, vulnerable, foolish, distressed, helpless, and discouraged. One candidate stated, "I know just how people who are new to the U.S. feel-lost, bewildered, and with a brain that is constantly overloaded. Even the simplest things, like trying to find clothes or food, become an expedition." Another candidate said:

What frustrates me the most is my limited ability to be able to communicate with people. I speak several languages, so often when I've traveled in the past I have been able to communicate effortlessly with people. This is not the case this time around. I wish I could understand and speak, but I can't, so this makes me feel helpless, and I do not like or enjoy this feeling of helplessness one bit. 
Emotion is a key component throughout all stages of transformative learning (Baumgartner, 2012; Dirkx, 2006). Strong emotion makes it less likely for a disorienting event to go unnoticed. Travelers' responses to events, whether dismissal or critical reflection, determine whether or not critical incidents facilitate the examination of previously invisible assumptions and expectations. Yet depending on strong emotions to surface assumptions and expectations is problematic. How many incidents went unnoticed because candidates found an "acceptable" explanation, thus maintaining oppressive beliefs and assumptions? How many incidents were simply judged as "wrong" never to be further analyzed?

\subsection{Stage two: Frame of reference examination}

\subsubsection{Expanding understanding beyond home culture prior knowledge}

This theme represents students' attempt to examine expectations and assumptions through the lens of theory and coursework. The practicum experience provided candidates with many opportunities to be the cultural other. The task of self-examination was challenging; teacher candidates struggled with identifying their emotions and thoughts as well as finding language to talk about the concepts. As a part of the structure to promote cultural engagement, we asked candidates to consider their practicum through the lens of theory. They drew on theories from their coursework as they "wrestled" to find the words and concepts for self-examination. For example, the following candidate used the language of Krashen's "affective filter" hypothesis to identify his emotional reactions to interacting with host families.

Well as far as the language piece, I just finished doing the ESOL endorsement. I graduated so I was done with that whole program and I was just noticing all of these things we just talked about in classes, like the reality of the affective filter. I've never experienced it before. I found I could finally relax with my host family and then I went over to Scott's host house and it was like affective filter right back up. I didn't even want to say, "Hello."

For other teacher candidates, coursework helped them think through interpretations of experiences in the host country. This is represented by the following quote:

Our latest course reading spoke to the importance of being a learner as well as an educator. My experience in Quito has allowed me the time to process the importance of what we are learning at [the university]. It is not one thing, experience, child or trip, it is all the little things, the cross connections.

Building a scaffold for culturally responsive teaching requires more than the individual elements of scaffolding; candidates must also see and make connections. Reflecting on disequilibrium through the lens of theory encouraged connections between the practicum and university coursework and provided language to consider disorienting events through multiple perspectives.

\subsubsection{Comparing differences: Resulting in judgment, questions, and new perspectives}

As a part of this theme, we identified Stage Two transformative learning elements aligned with Cranton's (2002) expanded phases: recognition of unconscious assumptions, questioning assumptions, and a willingness to consider other perspectives. For part of the reflection process, we asked students to compare the host and home cultures. Students approached these comparisons in three ways: comparisons that resulted in (a) value judgments about the home or host country, (b) questions, and (c) new perspectives. There were some who did not participate in self-examination, simply judging the new cultural experiences or norms as right or wrong if they differed from the home culture. For instance, candidates made judgments as they compared teacher/student interactions at host schools with personal school experiences in the U.S. and understanding of best practice.

As I looked at the equipment, I was sad for the children. The disparity between the beautiful parks I had taken my son to and this one was disturbing. I realized I would never let my own son attend this school. I would have been outraged and removed him the first day.

There was no consideration or discussion of the context or external factors-only an evaluation of the differences between expectations and experiences. In general, these judgments did not exemplify frame of reference examination; they were negative and reflected unconscious personal and cultural values. In future research we want to explore additional structures to facilitate movement from judgment to critical reflection and analysis to meet the needs of these students.

In the second group, teacher candidates engaged in critical reflection and moved past value judgments to examine their experiences through questioning. Analysis extended initial emotional interactions with cognitive considerations. Their questions included reflection on the potential reasons behind these differences and their own roles or potential action steps. In their reflections, teacher candidates mentioned how these experiences caused them to reexamine their own beliefs. The following excerpt is an example of analysis through questioning:

I am questioning my own thinking and attempting to sort out what is really needful. Do children in Ecuador need a different type of education than children in America? Do they need computers and books and high expectations set by teachers? Will their lives and opportunities be different from ours? 
Although student reflections did not fall orderly into transformative learning phases, this quote represents students who responded to home/host culture comparisons by identifying and questioning unconscious assumptions with a willingness to consider other perspectives (Cranton, 2002).

In the third group, the analysis did not end with comparing and contrasting; it led to further questioning and adjusted perspectives. In some cases, candidates reassessed how they viewed or judged experiences in both the host and home countries and cited the immersion experience as an opportunity for growth. One teacher candidate wrote:

I saw the difference, started digesting it and was accepting of the differences. As time goes on, I see the differences but I don't see it so much as a negative thing but more for me to learn from. I do think that Ecuador schools do the best they can with the little resources they have. The teachers are underpaid and many don't have the training that I am getting at this time. I am utilizing the differences as a plus to learn from the culture and the school system as well as hopefully be a resource to the teachers I come into contact with.

This candidate considered new perspectives about differences and the mutual benefits of the practicum to both her and the members of the majority culture. In these reflections students demonstrated self-examination, a willingness to question assumptions, and shifts in perspective.

The data included many examples of teacher candidates who went beyond examining the disorienting dilemmas to examine their own resulting thoughts, feelings, and actions. The most common instances of examination occurred through questioning, such as "Why is this situation so frustrating to me?" Some participants would ask a single question followed by further reflection and analysis while others asked series of questions, each building on the last. The structured reflection surrounding cultural comparisons triggered many instances of transformative learning elements in Stage two: Frame of reference examination.

\subsubsection{Peer processing of the disequilibrium that resulted from cultural immersion}

Participants reported that debriefing circles also promoted self-examination. They were able to identify and process their feelings and better understand their thoughts regarding the disorienting dilemmas-even though the process was not ideal. Many of the debriefing circle groups did not adhere to all of the protocols, particularly the one concerning "questions only, not advice." This is evident in students' reflections: "They [committee members] had very good insights and suggestions" and "At first I was hesitant to share and even had a negative attitude toward the debriefing circle. However, I had a great talk with the people in my group." The debriefing circle was designed to help the focus person examine his/her own thoughts and feelings through the questions of group members-not conversation. Although student reflections demonstrated a lack of strict adherence to all of the guidelines, they also included many references to the advantages of peer processing.

Teacher candidates described the process of discourse with their community of peers as an opportunity to share critical incidents in a setting where their peers listened with full attention, without judgment, and with sensitivity. One student stated, "Two of my traveling companions and I were able to get some strong emotions out into the open, and I think all three of us benefited from the opportunity to process our feelings and experiences in a completely non-judgmental environment." Other candidates referred to the quality of listening that occurred:

The attention was wonderful to have as you talked about your critical incident. The deep listening helps people talk more openly. . . I felt comfortable to talk openly about my incident and not have anyone judge me for my thoughts. I was able to speak freely and try to comprehend my thoughts more because I didn't have interruptions or distractions.

Teacher candidates reported being able to name and define their feelings, gain a better understanding of their thoughts and perspectives, and continue to process their experiences. One student said, "They caused me to think about my situations or feelings deeper and from different angles to solve the problem instead of just stewing over it more with no results." Another said, "I often struggle to define my feelings, so these times were great for me to be able to wrestle with words that helped me come to terms with my experiences." The candidates reported that the open and honest questions allowed them, as the focus person, to view their experiences from different perspectives and to contemplate questions that they had not considered. Our initial implementation of this reflection tool could be enhanced by future research of its strengths and weaknesses. The debriefing circles provided potential opportunities for candidates to experience frame of reference examination as discussed by Cranton's (2002) dialog phase (without the consensus component) and Mezirow's (2012) phases-self examination, critical assessment of assumptions, and recognition that the disequilibrium and transformative process are shared.

\subsection{Stage three: Transformative change}

Stage three includes a range of possible outcomes: altering assumptions and perspectives, putting new perspective into words, taking action based on revised perspectives, and returning the frame of reference to the unconscious as new roles, relationships, and actions are integrated (Cranton, 2002; Mezirow, 2012). These outcomes range from subtle discernment changes to visible and measurable shifts, such as challenging dominant ideologies rather than unconsciously accepting societal norms. From a critical theory perspective, Brookfield (2012) states, "In the process we alter how we see ourselves, our purpose in the world, and the way that purpose can be realized" (p. 142). As expected in a short-term cultural immersion practicum, candidates did not demonstrate Mezirow's "taking action" phases-such as planning for action, acquiring the 
necessary knowledge and skills to try new roles, building competence and confidence, and reintegrating based on new perspectives.

However, candidates did report altered perspectives and assumptions as well as initial attempts to put these shifts into words. Their reflections contained numerous instances of the following two sentence stems: "I now know what it feels like to-," and "I have a better/deeper/more concrete understanding of-." Participants described greater awareness, selfdiscovery, and new perspectives-connected by one common emotional theme: empathy. The following journal excerpt represents this theme:

This trip has completely changed how I feel about language minorities. It has definitely taught me to feel compassion and empathy for all minorities in my classroom. I may not feel the same as my minority students, but I think the first step toward bridging a gap between the two is understanding where they have come from and caring. Not all students will fit into a teacher's mold, so how will the teacher mold for the student?

This candidate's reflection provides an example of Taylor's (1994) "readiness for change" concept. She aptly uses the phrase "first step." This shift in perspective demonstrates a higher value on connecting with students from diverse backgrounds and moving away from the "one-size-fits-all" curriculum. Teachers who work with diverse students need to be skilled at recognizing and identifying student culture to engage minority students in learning that is meaningful and accessible (McIntyre et al., 2001). Once a student's culture is valued, it becomes a resource that allows teachers to learn from their students and develop a pedagogy that better supports student diversity (Gonzaléz, Moll, \& Amanti, 2005).

Teachers also discussed a change in their own perspectives. Possibly due to the short-term experience, our findings aligned more closely with Whitney's (2008) resolve to reorient future actions rather than Mezirow's specific plans for action. In her study of transformative learning in the context of the National Writing Projects' Summer Institute, Whitney did not find the presence of direct action plans but instead found a '"resolve to reorient' future actions according to changed perspectives" (p. 169). Teacher candidates expressed a resolve to reorient future actions as classroom teachers, such as a desire to be sensitive to the learning needs of their P-12 students.

Having a giant understanding for the fact that maybe the last little bit of the day there's not going to be a lot of learning going on. There's going to be a whole lot of "Gosh, I'm so tired!" The understanding that as a classroom teacher with ELL students I give them a lot of time to recover-maybe taking the time to read a book in Spanish or to have an extra few minutes doing something else-because I felt overwhelmed and at thirty years old to feel overwhelmed was horrible and I have good coping skills.

Disorienting events and examination of frames of reference led teachers to explore new roles, relationships, and actions. Exploring and reflecting on the role of minority was prominent in the data.

Let me say that being in a language minority is a horrible feeling. It's constricting and binding, emotionally draining, and you don't feel like yourself. This experience has opened my eyes in a way that nothing else could have. Now I have a much better understanding of ELLs etc. in the U.S. Specifically, I have a much better grasp on how some of my future students may feel. I believe this trip requires a lot of responsibility of me in the aftermath, but I may not have a full realization of it all until I'm confronted with specific situations in the U.S. Thus far, I believe I have the responsibility to be more culturally aware of world events and customs. I've gained an understanding of what I want to see and don't want to see in my classroom. I most certainly have a responsibility of modeling gratefulness; of expressing gratitude for the many blessings we have as Americans. I want to model for my students an expanded vision, an understanding and awareness of others, and especially an awareness of how people and their customs (whether from country-to-country or simply home-to-home) are different, not necessarily better or worse.

This candidate expresses a resolve to reorient and discusses specific targets for change. Yet the candidate's reorientation is limited to removing barriers for children. The candidate misses the mark when it comes to the goal of cultural engagement of incorporating student culture in the classroom (Bishop, 2005).

\subsection{Limitations of the study and future research}

The scope of intercultural competence cannot be addressed in a single experience or diversity course (Quezada, 2004; Trilokekar \& Kukar, 2011; Villegas \& Lucas, 2002); preparing interculturally competent teachers must be incorporated throughout the entire teacher education curriculum. As Berg et al. (2009) conclude from results of the Georgetown Consortium Study, "Being exposed to cultures different from their [study abroad students] home cultures turned out to be a necessary, though not a sufficient, condition for their intercultural learning" (p. 25). In the current study we did not expect candidates' overall measure of intercultural competence to significantly change in three weeks; instead, we explored conditions that could facilitate the preparation of interculturally competent teachers. Our work was limited to transformative learning elements as seen in candidates' reflections.

Another limitation was the lack of faculty guidance during the structured debriefing circles due to the guidelines of Palmer's (2004) clearness committee structure, designed to promote trust and protect confidentiality. Therefore, researchers did not control what was processed during these sessions, and some candidates were not challenged to process assumptions 
that could be considered eurocentric or judgmental. Some of these assumptions are apparent in the reflections quoted in Section 4.

It is also important to note that participants retained many forms of power and privilege as overseas travelers from the United States and China. While cultural immersion removes students from some of the patterns of power and privilege that they experience in their home cultures, they retain aspects of these patterns. For example, the majority of candidates represented middle-class socioeconomic status in the United States or upper-class status in China. The students did not receive scholarships to participate in the program; most covered the cost of their travel through bank loans, savings, or family gifts-limiting the candidate sample to those who could afford to travel overseas.

This study, in part, was a response to the future research recommendations from the MAT cultural immersion program year-one findings (Addleman et al., 2011), in which candidates reported that dialog sometimes reinforced the shame and embarrassment of disequilibrium rather than encouraging self reflection and the ability to consider multiple perspectives. Therefore, we implemented debriefing circles to promote self reflective dialog rather than shame-structured group interaction to encourage listening in a way that encourages self reflection and multiple perspectives (Palmer, 2004). Based on the findings in Section 4.2, the dialog framework holds promise, but we recommend further research regarding its strengths and weaknesses to better implement it as a reflection instrument for short-term immersion experiences.

Another direction for future research relates to the Georgetown Consortium Project and their findings related to interaction with peers, host families, and faculty. Students scored significantly higher on the Intercultural Development Inventory (Bennett, 2012) when they lived with other U.S. students, lived with host families with whom they spent more than 25\% of their free time (Berg et al., 2009), or were guided through the reflection and learning process by cultural mentors: "the presence or absence of a well-trained cultural mentor who meets frequently with students may be the single most important intervention to improve student intercultural learning abroad" (p. 25). In the current study, faculty members accompanied each group for the entire duration of the trip and used informal opportunities to act as cultural mentors, helping students to reflect on their learning and experiences, but formal reflection opportunities were limited to students' written reflections and small group debriefing circles. What benefits would result from formal cultural mentoring by faculty members? How can the Georgetown Consortium Project findings listed above be studied in a short-term program and effectively implemented in relation to frame of reference awareness and reflection to help prepare preservice teachers for work with culturally and linguistically diverse students?

\section{Conclusion}

Culturally responsive teaching requires the knowledge and skills of effective curriculum and instruction as well as intercultural competence influenced by self-awareness, empathy, cultural sensitivity, and critical reflection. How can teacher education programs scaffold intercultural competence for candidates who may not demonstrate a "readiness for change" (Taylor, 1994) or "supportive attitudes, beliefs, and understandings regarding multiculturalism and linguistic diversity" (Markos \& Steeg, 2012, p. 220)? In the current study, we examined cultural immersion as the context for facilitating a readiness for change.

Elements of transformative learning were clearly evident in the short-term practicum, as teacher candidates navigated the disequilibrium of a cultural immersion context. We identified five themes in the data that addressed the question, "What elements of transformative learning are triggered during a structured short-term cultural immersion experience?" The first theme, (1) critical incidents as triggering events, aligned with Stage One in the visual model of transformative learning (Fig. 1). Cultural immersion provided unique opportunities for participants to experience situations where they held less knowledge and control than in their home cultures. If confronted with the same situations at home, the teacher candidates may quickly dismiss the event due to assimilated assumptions. The next three themes aligned with Stage Two, frame of reference examination: (2) building schema through connections to theory and university coursework; (3) comparing differences-resulting in judgment, questions, and new perspectives; and (4) peer processing of disequilibrium. In a three-week span that could easily promote cultural tourism, we attempted to structure the practicum to maximize critical reflection through cultural engagement. Future research directions involve evaluating the strengths and weaknesses of prefield workshops, structured reflections, home stays, community involvement, and debriefing circles in order to increase cultural engagement in shortterm practicum experiences. Our final theme, (5) self-discovery, new perspectives, and a resolve to reorient, aligned with the third stage: potential transformative change.

Teacher candidates often complete coursework in educational and multicultural theory; however, that theoretical knowledge alone may not be adequate or persuasive enough to change beliefs and assumptions about students from diverse backgrounds.

I am definitely one step (if not 2 or 3 steps) ahead of where I would be if I had stayed home. I leave with the beginnings of an understanding of how it feels to be a minority, and I will be able to bring that cultural sensitivity to my [university] classes and my teaching. In short, although this trip has been overwhelming and humbling, I have nothing but gratitude for the opportunity.

We advocate for the strength of structured cultural immersion programs to disorient students' frameworks and allow them to reanalyze the cultural and intellectual biases they hold. 


\section{References}

Adachie, C. N. (2009). The danger of a single story. Retrieved from Ted.com, http://www.ted.com/talks/chimamanda_adichie_the_danger_of_a_single_story Addleman, R. A., Brazo, C. J., \& Cevallos, T. (2011). Transformative learning through cultural immersion. Northwest Passage: Journal of Educational Practices, $9(1), 55-67$.

Banks, J. A. (2004). Teaching for social justice, diversity, and citizenship in a global world. The Educational Forum, 68(4), 296-305. http://dx.doi.org/10.1080/00131720408984645

Banks, J. A. (2006). Improving race relations in schools: From theory and research to practice. Journal of Social Issues, 62(3), 607-614. http://dx.doi.org/10.1111/j.1540-4560.2006.00476

Banks, J. A., \& Banks, C. A. M. (2010). Multicultural education: Issues and perspectives (7th ed.). Hoboken, NJ: John Wiley \& Sons.

Banks, J., Cochran-Smith, M., Moll, L., Richert, A., Zeichner, K., LePage, P., et al. (2005). Teaching diverse learners. In L. Darling-Hammond, \& J. Bransford (Eds.), Preparing teachers for a changing world: What teachers should learn and be able to do (pp. 232-274). San Francisco: Jossey-Bass.

Baumgartner, L. M. (2001). An update on transformative learning. New Directions for Adult and Continuing Education, 89, 15-24.

Baumgartner, L. M. (2012). Mezirow's theory of transformative learning from 1975 to present. In E. W. Taylor, \& P. Cranton (Eds.), The handbook of transformative learning: Theory, research, and practice (pp. 99-114). San Francisco: John Wiley \& Sons Inc.

Bennett, M. J. (2012). Paradigmatic assumptions and a developmental approach to intercultural learning. In M. Vande Berg, R. M. Paige, \& K. H. Lou (Eds.), Student learning abroad: What our students are learning, what they're not, and what we can do about it (pp. 90-114). Sterling, VA: Stylus Publishing.

Berg, M. V., Connor-Linton, V., \& Paige, J. M. (2009). The Georgetown consortium project: Interventions for student learning abroad. Frontiers: The Interdisciplinary Journal of Study Abroad, 18, 1-75.

Bishop, R. (2005). Changing power relations in education: Kaupapa Mäori messages for "mainstream" education in Aotearoa/New Zealand. In F. Bodone (Ed.), What difference does research make E for whom? (pp. 253-269). New York: Peter Lang Publishing Inc.

Boyd, R. D., \& Myers, J. G. (1988). Transformative education. International Journal of Lifelong Education, 7(4), $261-284$

Brookfield, S. D. (2012). Critical theory and transformative learning. In E. W. Taylor, \& P. Cranton (Eds.), The handbook of transformative learning: Theory, research, and practice (pp. 131-145). San Francisco: John Wiley \& Sons Inc

Bruner, J. (1996). The culture of education. Cambridge, MA: Harvard University Press.

Charaniya, N. K. (2012). Cultural-spiritual perspective of transformative learning. In E. W. Taylor, \& P. Cranton (Eds.), The handbook of transformative learning: Theory, research, and practice (pp. 231-244). San Francisco: John Wiley \& Sons Inc.

Cordeiro, P. A. (2007). A modest proposal for the improvement of scholarship in internationalizing teacher education. Teacher Education Quarterly, 34(1), $151-155$.

Cranton, P. (2002). Teaching for transformation. New Directions for Adult E' Continuing Education, 93, 63-71.

Cranton, P., \& Taylor, E. W. (2012). Transformative learning theory: Seeking a more unified theory. In E. W. Taylor, \& P. Cranton (Eds.), The handbook of transformative learning: Theory, research, and practice (pp. 3-19). San Francisco: John Wiley \& Sons Inc.

Creswell, J. W. (2007). Qualitative inquiry and research design: Choosing among five approaches (2nd ed.). Thousand Oaks, CA: Sage.

Cruickshank, K., \& Westbrook, R. (2013). Local and global - conflicting perspectives? The place of overseas practicum in preservice teacher education. Asia-Pacific Journal of Teacher Education, 41(1), 55-68. http://dx.doi.org/10.1080/1359866X.2012.753989

Cushner, K. (2011). Intercultural research in teacher education: An essential intersection in the preparation of globally competent teachers. Action in Teacher Education, 33(5-6), 601-614. http://dx.doi.org/10.1080/01626620.2011.627306

Cushner, K. (2012). Intercultural competence for teaching and learning. In B. D. Shaklee, \& S. Baily (Eds.), Internationalizing teacher education in the United States [Kindle]. Lanham, MD: Rowman \& Littlefield Publishers Inc.

Dantas, M. L. (2007). Building teacher competency to work with diverse learners in the context of international education. Teacher Education Quarterly, 34(1), 75-95.

Deardorff, D. K. (2006). Identification and assessment of intercultural competence as a student outcome of internationalization. Journal of Studies in International Education, 10(3), 241-266. http://dx.doi.org/10.1177/1028315306287002

Dirkx, J. M. (2006). Engaging emotions in adult learning: A Jungian perspective on emotion and transformative learning. New Directions for Adult and Continuing Education, 109, 15-26.

Felps, W., Mitchell, T. R., \& Byington, E. (2006). How, when, and why bad apples spoil the barrel: Negative group members and dysfuntional groups. Research in Organizational Behavior, 27, 175-222. http://dx.doi.org/10.1016/S0191-3085(06)27005-9

Freire, P. (1970). Pedagogy of the oppressed. New York: Herder \& Herder.

Gonzaléz, N., Moll, L., \& Amanti, C. (2005). Funds of knowledge: Theorizing practices in households, communities, and classrooms. Mahwah, NJ: Lawrence Erlbaum Associates.

Habermas, J. (1971). Knowledge and human interests. Boston: Beacon Press.

Jensen, E. (2009). Teaching with poverty in mind: What being poor does to kids' brains and what schools can do about it. Alexandria: ASCD.

Johnson-Bailey, J. (2012). Positionality and transformative learning. In E. W. Taylor, \& P. Cranton (Eds.), The handbook of transformative learning: Theory, research, and practice (pp. 260-273). San Francisco: John Wiley \& Sons Inc.

Kitchenham, A. (2008). The evolution of John Mezirow's transformative learning theory. Journal of Transformative Education, 6(2), 104-123.

Kucukaydin, I., \& Cranton, P. (2012). Critically questioning the discourse of transformative learning theory. Adult Education Quarterly, 63(1), 43-56.

MacKeracher, D. (2012). The role of experience in transformative learning. In E. W. Taylor, \& P. Cranton (Eds.), The handbook of transformative learning: Theory, research, and practice (pp. 342-353). San Francisco: John Wiley \& Sons Inc.

Mahon, J., \& Cushner, K. (2007). The impact of overseas student teaching on personal and professional development. In K. Cushner, \& S. Brennan (Eds.), Intercultural student teaching: A bridge to global competence (pp. 57-87). Lanham: Rowman \& Littlefield Education.

Mahon, J., \& Espinetti, G. L. (2007). Establishing and maintaining an international student-teaching program. In K. Cushner, \& S. Brennan (Eds.), Intercultural student teaching: A bridge to global competence (pp. 13-33). Lanham: Rowman \& Littlefield Education.

Malewski, E., \& Phillion, J. (2009). International field experiences: The impact of class, gender and race on the perceptions and experiences of preservice teachers. Teaching and Teacher Education, 25(1), 52-60.

Malewski, E., Sharma, S., \& Phillion, J. (2012). How international field experiences promote cross-cultural awareness in preservice teachers through experiential learning: Findings from a six-year collective case study. Teachers College Record, 114(8), 1-44.

Markos, A., \& Steeg, S. M. (2012). Preservice teachers' understanding about ELLs: One pedagogical tool for identifying and shifting dispositions. In M. T. Cowart, \& G. Anderson (Eds.), English language learners in 21st century classrooms: Challenges and expectations (pp. 218-243). Federation of North Texas Area Universities.

Marx, H., \& Moss, D. M. (2011). Please mind the culture gap: Intercultural development during a teacher education study abroad program. Journal of Teacher Education, 62(1), 35-47. http://dx.doi.org/10.1177/0022487110381998

McIntosh, P. (1989). White privilege: Unpacking the invisible knapsack. Peace and Freedom Magazine, (July/August), 10-12.

McIntyre, E., Rosebery, A., \& González, N. (2001). Classroom diversity: Connecting curriculum to students' lives. Portsmouth, NH: Heinemann.

McLaren, P., \& Farahmandpur, R. (2001). Teaching against globalization and the new imperialism: Toward a revolutionary pedagogy. Journal of Teacher Education, 52(2), 136-150. http://dx.doi.org/10.1177/0022487101052002005

Merriam, S. B., \& Kim, S. (2012). Studying transformative learning: What methodology? In E. W. Taylor, \& P. Cranton (Eds.), The handbook of transformative learning: Theory, research, and practice (pp. 56-72). San Francisco: John Wiley \& Sons Inc.

Merryfield, M. M. (2000). Why aren't teachers being prepared to teach for diversity, equity, and global interconnectedness? A study of lived experiences in the making of multicultural and global educators. Teaching and Teacher Education, 16, 429-443. 
Mezirow, J. (1990). How critical reflection triggers transformative learning. In J. Mezirow (Ed.), Fostering critical reflection in adulthood: A guide to transformative and emancipatory learning (pp. 1-20). San Francisco: Jossey-Bass Inc.

Mezirow, J. (1997). Transformative learning: Theory to practice. New Directions for Adult and Continuing Education, 74, 5-12.

Mezirow, J. (2000). Learning to think like an adult: Core concepts of transformation theory. In J. Mezirow (Ed.), Learning as transformation: Critical perspectives on a theory in progress (pp. 3-34). San Francisco: Jossey-Bass Inc.

Mezirow, J. (2012). Learning to think like an adult: Core concepts of transformation theory. In E. W. Taylor, \& P. Cranton (Eds.), The handbook of transformative learning: Theory, research, and practice (pp. 73-94). San Francisco: John Wiley \& Sons Inc.

Moll, L. C., Amanti, C., Neff, D., \& Gonzaléz, N. (1992). Funds of knowledge for teaching: Using a qualitative approach to connect homes and classrooms. Theory Into Practice, 31(2), 132-141.

Palmer, P. J. (2004). A hidden wholeness: A journey toward an undivided life. San Francisco: Jossey-Bass.

Pence, H. M., \& Macgillivray, I. K. (2008). The impact of an international field experience on preservice teachers. Teaching and Teacher Education, 24(1), 14-25. http://dx.doi.org/10.1016/j.tate.2007.01.003

Phillion, J., Malewski, E. L., Sharma, S., \& Wang, Y. (2009). Reimagining the curriculum: Future teachers and study abroad. Frontiers: The Interdisciplinary Journal of Study Abroad, 18, 323-339.

Quezada, R. L. (2004). Beyond educational tourism: Lessons learned while student teaching abroad. International Education Journal, 5(4), 458-465.

Rios, F., Montecinos, C., \& Olphen, M. Van. (2007). Lessons learned from a collaborative self-study in international teacher education: Visiones, preguntas, y desafios. Teacher Education Quarterly, 34(1), 57-74.

Rossman, G. B., \& Rallis, S. F. (2003). Learning in the field: An introduction to qualitative research (2nd ed.). Thousand Oaks, CA: Sage Publications.

Shaklee, B. D., \& Baily, S. (2012). A framework for internationalizing teacher preparation. In B. D. Shaklee, \& S. Baily (Eds.), Internationalizing teacher education in the United States [Kindle]. Lanham, MD: Rowman \& Littlefield Publishers Inc.

Sleeter, C. E. (2001). Preparing teachers for culturally diverse schools research and the overwhelming presence of whiteness. Journal of Teacher Education, 52(2), 94-106.

Spitzberg, B. H., \& Changnon, G. (2009). Conceptualizing intercultural competence. In D. K. Deardorff (Ed.), The SAGE handbook of intercultural competence (pp. 2-52). Los Angeles: SAGE Publications Inc.

Stachowski, L. L., \& Brantmeier, E. J. (2002). Understanding self through the other: Changes in student teacher perceptions of home culture from immersion in Navajoland and overseas. International Education, 32(1), 5-18.

Stachowski, L. L. (2007). A world of possibilities within the United States: Integrating meaningful domestic intercultural teaching experiences into teacher education. In K. Cushner, \& S. Brennan (Eds.), Intercultural student teaching: A bridge to global competence (pp. 88-122). Lanham: Rowman \& Littlefield Education.

Staples, B. (2005). Just walk on by: Black men and public space. In R. DiYanni (Ed.), One hundred great essays (2nd ed., pp. 690-694). New York: Pearson Education.

Steves, R. (2009). Travel as a political act. New York: Nation Books.

Storti, C. (1999). Figuring foreigners out: A practical guide. Yarmouth, ME: Intercultural Press.

Taylor, E. W. (1994). Intercultural competency: A transformative learning process. Adult Education Quarterly, 44(3), 154-174.

Trilokekar, R. D., \& Kukar, P. (2011). Disorienting experiences during study abroad: Reflections of pre-service teacher candidates. Teaching and Teacher Education, 27(7), 1141-1150. http://dx.doi.org/10.1016/j.tate.2011.06.002

Van Manen, M. (1990). Researching lived experiences: Human science for an action sensitive pedagogy. Albany, NY: State University of New York Press.

Villegas, A., \& Lucas, T. (2002). Preparing culturally responsive teachers: Rethinking the curriculum. Journal of Teacher Education, 53(1), 20-32.

Whitney, A. (2008). Teacher transformation in the National Writing Project. Research in the Teaching of English, 43(2), 144-187.

Zhao, Y., Meyers, L., \& Meyers, B. (2009). Cross-cultural immersion in China: Preparing pre-service elementary teachers to work with diverse student populations in the United States. Asia-Pacific Journal of Teacher Education, 37(3), 295-317. http://dx.doi.org/10.1080/13598660903058925 